Journal of Advanced Research in Fluid Mechanics and Thermal Sciences

Journal homepage: www.akademiabaru.com/arfmts.html ISSN: 2289-7879

\title{
Three-Dimensional Radiative Flow of Hybrid Nanofluid Past a Shrinking Plate with Suction
}

\author{
Nur Syahirah Wahid ${ }^{1}$, Norihan Md Arifin ${ }^{1,2,}{ }^{*}$, Najiyah Safwa Khashi'ie ${ }^{3}$, Rusya Iryanti Yahaya ${ }^{2}$, Ioan \\ Pop $^{4}$, Norfifah Bachok ${ }^{1,2}$, Mohd Ezad Hafidz Hafidzuddin ${ }^{5}$ \\ Department of Mathematics, Faculty of Science, Universiti Putra Malaysia, 43400 UPM Serdang, Selangor, Malaysia \\ 2 Institute for Mathematical Research, Universiti Putra Malaysia, 43400 UPM Serdang, Selangor, Malaysia \\ 3 Fakulti Teknologi Kejuruteraan Mekanikal dan Pembuatan, Universiti Teknikal Malaysia Melaka, Hang Tuah Jaya, 76100 Durian Tunggal, Melaka, \\ Malaysia \\ 4 Department of Mathematics, Babeş-Bolyai University, R-400084 Cluj-Napoca, Romania \\ 5 Centre of Foundation Studies for Agricultural Science, Universiti Putra Malaysia, 43400 UPM Serdang, Selangor, Malaysia
}

\section{ARTICLE INFO}

\section{Article history:}

Received 3 May 2021

Received in revised form 28 June 2021

Accepted 2 July 2021

Available online 28 July 2021

\section{Keywords:}

Boundary layer; Hybrid nanofluid; radiation; Shrinking plate

\section{ABSTRACT}

Hybrid nanofluid has been widely used in various heat transfer applications especially as the heat exchanger due to the great thermal conductivity compared to the conventional fluid. However, numerous investigations should still be carried out to properly understand its properties. Hence, in this study, a three-dimensional radiative flow of hybrid $\mathrm{Cu}-\mathrm{Al}_{2} \mathrm{O}_{3}$ /water nanofluid past a permeable shrinking plate is numerically analyzed. The boundary layer including the energy equations are reduced to a system of ordinary differential equations using the similarity transformations and are then solved numerically by using the bvp4c solver in MATLAB. The application of suction through the permeable plate is necessary in aiding the fluid motion past the shrinking surface. Dual solutions are also observable; hence the stability analysis is conducted to mathematically validate the real solution. The enhancement of copper volumetric concentration in the hybrid nanofluid is capable in decelerating the boundary layer separation.

\section{Introduction}

The composition of dissimilar nanoparticles in a base fluid produces a latest generation of heat transfer fluid labelled as hybrid nanofluid. Two methods, namely the single-step method and the twostep method, are commonly applied for preparing hybrid nanofluids. According to Sidik et al., [1], for small-scale formation only the single-step method is normally required, while for mass formation, the two-step method will be implemented. The application of hybrid nanofluid ranges from industrial and engineering processes (e.g., as a coolant in a heat exchanger, transformer, and nuclear system) to biomedical uses (e.g., for drug delivery in blood circulation), prompts various research to examine the rheological behaviour and the properties of heat transfer for hybrid nanofluids.

\footnotetext{
* Corresponding author.

E-mail address: norihana@upm.edu.my
}

https://doi.org/10.37934/arfmts.85.1.5470 
Suresh et al., [2] discussed the preparation of aqueous $\mathrm{Cu}-\mathrm{Al}_{2} \mathrm{O}_{3}$ hybrid nanofluid, also experimentally researched the thermophysical properties and friction factor of this fluid. The friction factor and heat transfer of the studied hybrid nanofluid were greater in comparison to pure water. Then, Devi and Devi [3] developed the new thermophysical properties to study the impacts of magnetic field on $\mathrm{Cu}-\mathrm{Al}_{2} \mathrm{O}_{3}$ /water hybrid nanofluid flow at the boundary layer with the inclusion of suction over a stretching sheet. The hybrid nanofluid was contemplated to have a superior heat transfer rate in contrast to $\mathrm{Cu} /$ water nanofluid, and the suction parameter augments the rate of the heat transfer for both types of the fluids. Later, this study was extended by Devi and Devi [4] to a three-dimensional flow model with Newtonian heating. Meanwhile, Nadeem et al., [5] discovered that the thermal slip parameter recedes the temperature of the hybrid nanofluid in a threedimensional stagnation-point flow. The radiative effects on the three-dimensional flow of the hybrid nanofluid over a stretchable cylinder were then examined by Maskeen et al., [6]. The Nusselt number, that quantifies the heat transfer rate, got enhanced by the escalation of radiation parameter. Recently, Khashi'ie et al., [7] found the non-unique solutions in a problem involving the hybrid nanofluid in three-dimensional flow of past permeable and impermeable surfaces. However, only one of the solutions is stable as being revealed through the stability analysis. Other studies on $\mathrm{Cu}$ $\mathrm{Al}_{2} \mathrm{O}_{3}$ /water hybrid nanofluid particularly on the three-dimensional flow have been successfully accomplished by Abbas et al., [8], Zainal et al., [9], and Khashi'ie et al., [10]. The recent interesting studies concerning on the hybrid nanofluid with variety selection of hybrid nanoparticles, parameters and methods can be found in the research papers [11-23].

Motivated by the previous research on hybrid nanofluid, the current study considers the threedimensional boundary layer flow of hybrid $\mathrm{Cu}-\mathrm{Al}_{2} \mathrm{O}_{3}$ /water nanofluid over a permeable shrinking plate. Similarity transformations and bvp4c solver (MATLAB) are implemented to compute the solution numerically, and the results are analysed and scrutinized.

\section{Model Formulation}

Consider a steady, three-dimensional laminar, and incompressible hybrid nanofluid due to a permeable shrinking plate with the inclusion of thermal radiation effect and suction. The plate is deformed with a linear velocity function such that $u_{w}(x)=a x$ in $x$-direction and $v_{w}(y)=a y$ in $y-$ direction where $a$ is a constant as exhibited in Figure 1. A few of assumptions are also included for this physical model

i. Both hybrid nanoparticles and water are in the state of thermal equilibrium.

ii. The permeable plate assists the suction process.

iii. Both wall and far-field temperatures are fixed and represented by $T_{w}$ and $T_{\infty}$, respectively. 


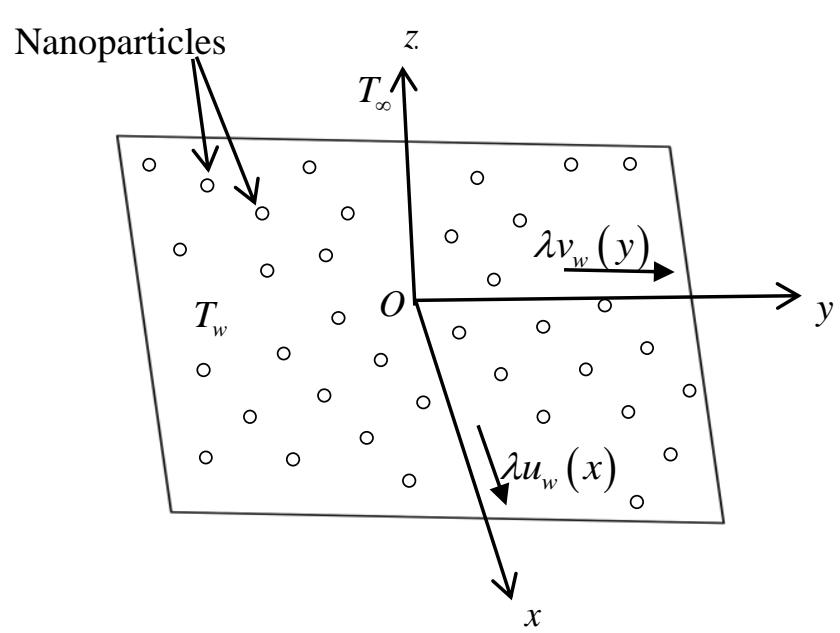

Fig. 1. The physical representation for the model

Applying and considering the boundary layer approximations as mentioned, the mathematical formulation for the model is given as [10]

$\frac{\partial u}{\partial x}+\frac{\partial v}{\partial y}+\frac{\partial w}{\partial z}=0$

$u \frac{\partial u}{\partial x}+v \frac{\partial u}{\partial y}+w \frac{\partial u}{\partial z}=v_{h n f} \frac{\partial^{2} u}{\partial z^{2}}$

$u \frac{\partial v}{\partial x}+v \frac{\partial v}{\partial y}+w \frac{\partial v}{\partial z}=v_{h n f} \frac{\partial^{2} v}{\partial z^{2}}$

$u \frac{\partial T}{\partial x}+v \frac{\partial T}{\partial y}+w \frac{\partial T}{\partial z}=\alpha_{h n f} \frac{\partial^{2} T}{\partial z^{2}}-\frac{1}{\left(\rho C_{p}\right)_{h n f}} \frac{\partial q_{r}}{\partial z}$,

subject to the conditions at the boundary

$$
\begin{gathered}
u(x, y, z)=\lambda u_{w}(x), \quad v(x, y, z)=\lambda v_{w}(y), \quad w(x, y, z)=w_{0}, \quad T(x, y, z)=T_{w}, \quad \text { at } \quad z=0, \\
u(x, y, z) \rightarrow 0, \quad v(x, y, z) \rightarrow 0, \quad T(x, y, z) \rightarrow T_{\infty}, \quad \text { as } \quad z \rightarrow \infty .
\end{gathered}
$$

Using Rosseland [24] approximation, the heat flux term for thermal radiation in energy Eq. (4) is simplified such that

$q_{r}=-\left(\frac{4 \sigma^{*}}{3 k^{*}}\right) \frac{\partial T^{4}}{\partial z}$

where $\sigma^{*}$ and $k^{*}$ are the constant of Stefan-Boltzman and the coefficient of mean absorption, accordingly. The term $T^{4}$ is expanded by using Taylor series so that $T^{4} \approx 4 T_{\infty}^{3} T-3 T_{\infty}^{4}$ after neglecting the higher-order terms. Energy Eq. (4) can now exemplify by 
$u \frac{\partial T}{\partial x}+v \frac{\partial T}{\partial y}+w \frac{\partial T}{\partial z}=\left(k_{h n f}+\frac{16 \sigma^{*} T_{\infty}^{3}}{3 k^{*}}\right) \frac{1}{\left(\rho C_{p}\right)_{h n f}} \frac{\partial^{2} T}{\partial z^{2}}$.

In this work, $u$ (in $x$-direction), $v$ (in $y$-direction) and $w$ (in $z$-direction) are the velocities, $T$ is the hybrid nanofluid temperature, $v_{h n f}=\mu_{h n f} / \rho_{h n f}$ and $\alpha_{h n f}=k_{h n f} /\left(\rho C_{p}\right)_{h n f}$ are the kinematic viscosity and the thermal diffusivity of the hybrid nanofluid, accordingly, $w_{0}=-S \sqrt{a v_{f}}$ is the mass flow that indicates the suction $\left(w_{0}<0\right)$ and injection $\left(w_{0}>0\right)$ for the flow.

The expression of thermophysical properties of traditional and hybrid nanofluids are presented in Table 1. For the hybrid nanofluid, the correlations by Takabi and Salehi [25] are fully adopted.

\section{Table 1}

The expression of thermophysical properties for nanofluid

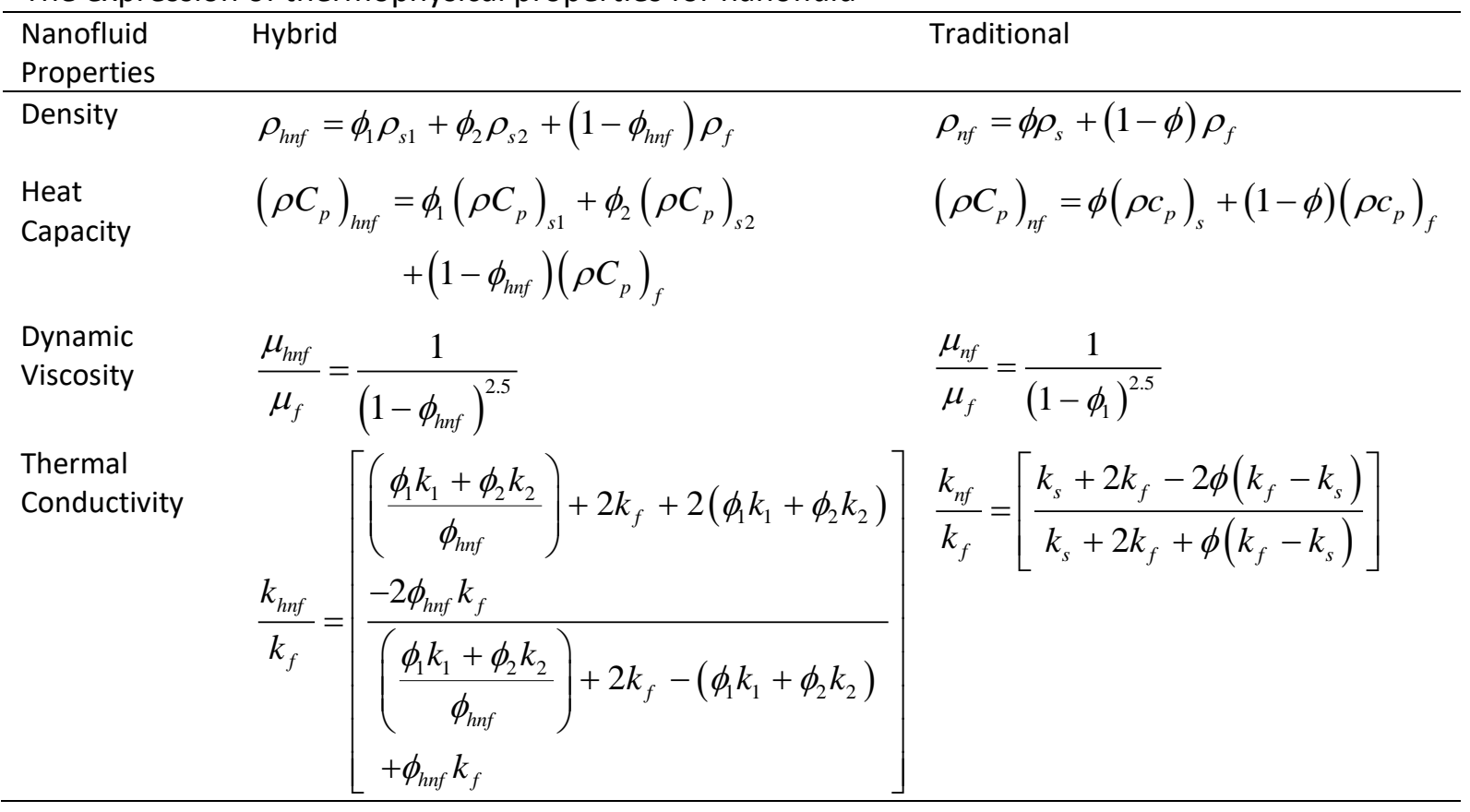

The subscripts $s 1$ and $s 2$ represent the nanoparticles (alumina and copper), whilst $f$, $n f$ and hnf symbolize the base fluid, the nanofluid, and the hybrid nanofluid, severally. The nanoparticles volumetric concentration is denoted by $\phi_{1}$ for alumina nanoparticle and $\phi_{2}$ for copper nanoparticle with the hybrid nanoparticles volumetric concentration that is equated as $\phi_{h n f}=\phi_{1}+\phi_{2}$. Also, the related thermophysical properties are displayed in Table 2 , which these properties are as according to Oztop and Abu-Nada [26].

Table 2

Thermophysical properties of nanoparticles and water

\begin{tabular}{llll}
\hline Properties & $\rho\left(\mathrm{kg} / \mathrm{m}^{3}\right)$ & $C_{p}(\mathrm{~J} / \mathrm{kgK})$ & $k(\mathrm{~W} / \mathrm{mK})$ \\
\hline Alumina & 3970 & 765 & 40 \\
Copper & 8933 & 385 & 400 \\
Water & 997.1 & 4179 & 0.6130 \\
\hline
\end{tabular}


The subsequent similarity variables (transformations) are implemented to simplify the complexity of Eq. (2), Eq. (3) and Eq. (7)

$$
\eta=z \sqrt{\frac{a}{v_{f}}}, u=a x f^{\prime}(\eta), \quad v=a y g^{\prime}(\eta), \quad w=-\sqrt{a v_{f}}[f(\eta)+g(\eta)], \quad \theta(\eta)=\frac{T-T_{\infty}}{T_{w}-T_{\infty}}
$$

It is worth pointing out that these similarity transformations identically satisfy Eq. (1). Hence, the following ODEs are obtained:

$$
\begin{aligned}
& \left(\frac{\mu_{h n f} / \mu_{f}}{\rho_{h n f} / \rho_{f}}\right) f^{\prime \prime \prime}-f^{\prime 2}+(f+g) f^{\prime \prime}=0, \\
& \left(\frac{\mu_{h n f} / \mu_{f}}{\rho_{h n f} / \rho_{f}}\right) g^{\prime \prime \prime}-g^{\prime 2}+(f+g) g^{\prime \prime}=0, \\
& \frac{\left(\rho C_{p}\right)_{f}}{\left(\rho C_{p}\right)_{h n f}} \frac{1}{\operatorname{Pr}}\left(\frac{k_{h n f}}{k_{f}}+\frac{4}{3} R d\right) \theta^{\prime \prime}+(f+g) \theta^{\prime}=0,
\end{aligned}
$$

inclusive of the boundary conditions

$$
\begin{gathered}
f(\eta)=S, \quad f^{\prime}(\eta)=\lambda, \quad g(\eta)=0, \quad g^{\prime}(\eta)=\lambda, \quad \theta(\eta)=1, \quad \text { at } \quad \eta=0, \\
f^{\prime}(\eta) \rightarrow 0, \quad g^{\prime}(\eta) \rightarrow 0, \quad \theta(\eta) \rightarrow 0, \quad \text { as } \quad \eta \rightarrow \infty,
\end{gathered}
$$

where $S$ is the suction/injection parameter, $\operatorname{Pr}=\left(C_{p} \mu\right)_{f} / k_{f}$ is the Prandtl number, $\lambda$ is the stretching/shrinking parameter and $R d=4 \sigma^{*} T_{\infty}^{3} / k_{f} k^{*}$ is the thermal radiation parameter.

The skin friction coefficients $C_{f x}$ (in $x$-direction) and $C_{f y}$ (in $y$-direction) as well as the local Nusselt number $N u_{x}$, are respectively specified by [10]

$$
C_{f x}=\frac{\tau_{w x}}{\rho_{f} u_{w}^{2}}, C_{f y}=\frac{\tau_{w y}}{\rho_{f} v_{w}^{2}}, N u_{x}=\frac{x q_{w}}{k_{f}\left(T_{w}-T_{\infty}\right)},
$$

where the surface shear stresses and the surface heat flux, are specified as

$$
\tau_{w x}=\mu_{h n f}\left(\frac{\partial u}{\partial z}\right)_{z=0}, \tau_{w y}=\mu_{h n f}\left(\frac{\partial v}{\partial z}\right)_{z=0}, q_{w}=-k_{h n f}\left(\frac{\partial T}{\partial z}\right)_{z=0}+\left(q_{r}\right)_{z=0}
$$

Substituting Eq. (8) and Eq. (14) into Eq. (13), $C_{f x}, C_{f y}$ and $N u_{x}$ can be simplified as

$$
C_{f x} \operatorname{Re}_{x}^{1 / 2}=\frac{\mu_{h n f}}{\mu_{f}} f^{\prime \prime}(0), C_{f y} \operatorname{Re}_{y}^{1 / 2}=\frac{\mu_{h n f}}{\mu_{f}} g^{\prime \prime}(0), N u_{x} \operatorname{Re}_{x}^{-1 / 2}=-\left(\frac{k_{h n f}}{k_{f}}+\frac{4}{3} R d\right) \theta^{\prime}(0),
$$


respectively, where $\operatorname{Re}_{x}=x u_{w} / v_{f}$ and $\operatorname{Re}_{y}=y v_{w} / v_{f}$.

Eq. (9)-(11) together with the boundary conditions (12) are solved numerically by using the bvp4c solver in MATLAB with the appropriate values of parameter to compute the profiles and the main physical quantities. Further explanation on the numerical computation in the bvp4c solver can be seen in the published paper elucidated by Khashi'ie et al., [10].

\section{Stability Analysis}

The stability analysis execution requires a few steps, which firstly, as recommended by Merkin [27], Eq. (2), Eq. (3) and Eq. (7) need to be transformed into the unsteady state

$u \frac{\partial u}{\partial x}+v \frac{\partial u}{\partial y}+w \frac{\partial u}{\partial z}+\frac{\partial u}{\partial t}=v_{h n f} \frac{\partial^{2} u}{\partial z^{2}}$

$u \frac{\partial v}{\partial x}+v \frac{\partial v}{\partial y}+w \frac{\partial v}{\partial z}+\frac{\partial v}{\partial t}=v_{h n f} \frac{\partial^{2} v}{\partial z^{2}}$

$u \frac{\partial T}{\partial x}+v \frac{\partial T}{\partial y}+w \frac{\partial T}{\partial z}+\frac{\partial T}{\partial t}=\left(k_{h n f}+\frac{16 \sigma^{*} T_{\infty}^{3}}{3 k^{*}}\right) \frac{1}{\left(\rho C_{p}\right)_{h n f}} \frac{\partial^{2} T}{\partial z^{2}}$

and a new set of similarity transformations including the dimensionless time variable $\tau$ are introduced,

$$
\begin{gathered}
\eta=z \sqrt{\frac{a}{v_{f}}}, \quad \tau=a t, \quad \theta(\eta, \tau)=\frac{T-T_{\infty}}{T_{w}-T_{\infty}} \\
u=a x \frac{\partial f(\eta, \tau)}{\partial \eta}, \quad v=a y \frac{\partial g(\eta, \tau)}{\partial \eta}, \quad w=-\sqrt{a v_{f}}[f(\eta, \tau)+g(\eta, \tau)] .
\end{gathered}
$$

By applying the transformations (19) into Eq. (16)-(18), the equations are then transformed to:

$$
\begin{aligned}
& \left(\frac{\mu_{h n f} / \mu_{f}}{\rho_{h n f} / \rho_{f}}\right) \frac{\partial^{3} f}{\partial \eta^{3}}-\left(\frac{\partial f}{\partial \eta}\right)^{2}+(f+g) \frac{\partial^{2} f}{\partial \eta^{2}}-\frac{\partial^{2} f}{\partial \eta \partial \tau}=0, \\
& \left(\frac{\mu_{h n f} / \mu_{f}}{\rho_{h n f} / \rho_{f}}\right) \frac{\partial^{3} g}{\partial \eta^{3}}-\left(\frac{\partial g}{\partial \eta}\right)^{2}+(f+g) \frac{\partial^{2} g}{\partial \eta^{2}}-\frac{\partial^{2} g}{\partial \eta \partial \tau}=0, \\
& \frac{\left(\rho C_{p}\right)_{f}}{\left(\rho C_{p}\right)_{h n f}} \frac{1}{\operatorname{Pr}}\left(\frac{k_{h n f}}{k_{f}}+\frac{4}{3} R d\right) \frac{\partial^{2} \theta}{\partial \eta^{2}}+(f+g) \frac{\partial \theta}{\partial \eta}-\frac{\partial \theta}{\partial \tau}=0,
\end{aligned}
$$

conditioned to 


$$
\begin{gathered}
f(\eta, \tau)=S, \quad g(\eta, \tau)=0, \quad \frac{\partial f(\eta, \tau)}{\partial \eta}=\lambda, \quad \frac{\partial g(\eta, \tau)}{\partial \eta}=\lambda, \quad \theta(\eta, \tau)=1, \quad \text { at } \quad \eta=0, \\
\frac{\partial f(\eta, \tau)}{\partial \eta} \rightarrow 0, \quad \frac{\partial g(\eta, \tau)}{\partial \eta} \rightarrow 0, \quad \theta(\eta, \tau) \rightarrow 0, \quad \text { as } \quad \eta \rightarrow \infty .
\end{gathered}
$$

Then, the perturbation equations are adopted to test the solutions' stability which are equated as $[10,25]$

$$
\left.\begin{array}{ll}
f(\eta, \tau)=f_{0}(\eta)+e^{-\gamma \tau} F(\eta), & f(\eta)=f_{0}(\eta) \\
g(\eta, \tau)=g_{0}(\eta)+e^{-\gamma \tau} G(\eta), & g(\eta)=g_{0}(\eta) \\
\theta(\eta, \tau)=\theta_{0}(\eta)+e^{-\gamma \tau} H(\eta), & \theta(\eta)=\theta_{0}(\eta)
\end{array}\right\}
$$

where $F(\eta), G(\eta)$ and $H(\eta)$ are the small relative to $f_{0}(\eta), g_{0}(\eta)$ and $\theta_{0}(\eta)$, respectively, and $\gamma$ is the yet undetermined eigenvalue. Therefore, by employing Eq. (24) into Eq. (20)-(22), the linearized eigenvalue problem can be formulated as

$$
\begin{aligned}
& \left(\frac{\mu_{h n f} / \mu_{f}}{\rho_{h n f} / \rho_{f}}\right) F^{\prime \prime \prime}+\left(f_{0}+g_{0}\right) F^{\prime \prime}+(F+G) f_{0}^{\prime \prime}-\left(2 f_{0}^{\prime}-\gamma\right) F^{\prime}=0, \\
& \left(\frac{\mu_{h n f} / \mu_{f}}{\rho_{h n f} / \rho_{f}}\right) G^{\prime \prime \prime}+\left(f_{0}+g_{0}\right) G^{\prime \prime}+(F+G) g_{0}^{\prime \prime}-\left(2 g_{0}^{\prime}-\gamma\right) G^{\prime}=0, \\
& \frac{\left(\rho C_{p}\right)_{f}}{\left(\rho C_{p}\right)_{h n f}} \frac{1}{\operatorname{Pr}}\left(\frac{k_{h n f}}{k_{f}}+\frac{4}{3} R d\right) H^{\prime \prime}+(F+G) \theta_{0}^{\prime}+\left(f_{0}+g_{0}\right) H^{\prime}+\gamma H=0,
\end{aligned}
$$

and following the relaxation boundary conditions as recommended by Harris et al., [28], $\left(F^{\prime}(\eta) \rightarrow 0\right.$ is initially relaxed and reinstated with $F^{\prime \prime}(0)=1$ ) the boundary conditions are stated as

$$
\begin{gathered}
F(\eta)=0, \quad G(\eta)=0, \quad H(\eta)=0, \quad F^{\prime}(\eta)=0, \quad G^{\prime}(\eta)=0, \quad F^{\prime \prime}(\eta)=1, \quad \text { at } \quad \eta=0, \\
G^{\prime}(\eta) \rightarrow 0, \quad H(\eta) \rightarrow 0, \quad \text { as } \quad \eta \rightarrow \infty .
\end{gathered}
$$

The linearized eigenvalue problem (25)-(27) with (28) will be solved by the utilization of bvp4c solver to execute the eigenvalue $\gamma$. The smallest eigenvalue $\gamma$ will reveal the stability of the solutions, in which the smallest positive eigenvalue $(\gamma>0)$ deduces that the flow/solution is stable/real due to the initial decay of disturbance and otherwise. Additionally, instead of analysing on the sign (positive/negative) of the smallest eigenvalue, the stability of the solution can also be recognized by looking at the graphical representation of the solution towards the velocity and temperature profiles, the skin friction coefficient and the local Nusselt number. Normally, when there are dual solutions, the solution that is closer to the boundary or has the least boundary layer thickness is considered as the stable solution compared to the other one. Also, by looking through the graph of the skin friction coefficient and the local Nusselt number, the upper branch of the solution is said to be stable than the lower branch when there exist dual solutions. However, it is 
necessary to analyse the stability of the solution through the execution of the eigenvalues for a sophisticated validation.

\section{Results and Discussions}

The effects of volumetric concentration of copper $\phi_{2}$, thermal radiation $R d$, suction $S$, and stretching/shrinking surface $\lambda$ parameters are scrutinized in the model of boundary layer flow (three dimensional) of $\mathrm{Cu}-\mathrm{Al}_{2} \mathrm{O}_{3}$ /water hybrid nanofluid over a permeable shrinking plate. The mathematical formulation that governs such boundary layer flow model is solved and the numerical solutions are enumerated, assisted by bvp4c solver that is accessible in MATLAB. Certain related values for the boundary layer thickness, initial guesses and parameters are adjusted accordingly to ensure the accuracy of the solutions. For validation purposes, a comparison analysis has been performed for $-f$ "(0) and $-g$ "(0) obtained in this present study with the previous related models as tabulated in Table 3. The compared values are noticed to be well agreed, hence validate the numerical solutions together with the taken numerical procedure.

Table 3

$-f^{\prime \prime}(0)$ and $-g$ "(0) when $S=\phi_{1}=\phi_{2}=R d=0$ and $\lambda=1$ (stretching case)

\begin{tabular}{lll}
\hline & $-f^{\prime \prime}(0)$ & $-g^{\prime \prime}(0)$ \\
\hline Present (bvp4c) & 1.173721 & 1.173721 \\
Khashi'ie et al., [10] (bvp4c) & 1.173721 & 1.173721 \\
Jusoh et al., [29] (bvp4c) & 1.173721 & 1.173721 \\
Hayat et al., [30] (HAM) & 1.173721 & 1.173721 \\
\hline
\end{tabular}

In this study, we have fixed the value for Prandtl number, $\operatorname{Pr}=6.2$ and the volumetric concentration for alumina, $\phi_{1}=0.01$ thoroughly, while the other parameters are set to be varied with the appropriate range of values. Dual solutions are observable specifically when the surface is shrunk $(\lambda<0)$ with appropriate value of suction parameter $S$. The impact of volumetric concentration parameter $\phi_{2}$ for copper towards the skin friction coefficients $\operatorname{Re}_{x}{ }^{1 / 2} C_{f x}, \operatorname{Re}_{y}{ }^{1 / 2} C_{f y}$ against shrinking surface $(\lambda<0)$ and suction $S$ parameters are illustrated in Figure 2 and Figure 3 . The intensification of copper volumetric concentration parameter $\phi_{2}$ has intensified the skin friction coefficients $\operatorname{Re}_{x}^{1 / 2} C_{f x}, \operatorname{Re}_{y}{ }^{1 / 2} C_{f y}$ at the shrinking surface $(\lambda<0)$ for the first solution. In Figure 2 , the critical points which located in between the first and the second solutions are visible in the shrinking surface region, apparently at $\lambda_{c 1}=-1.8772\left(\phi_{2}=0.01\right), \lambda_{c 2}=-1.9199\left(\phi_{2}=0.015\right)$ and $\lambda_{c 3}=-1.9610\left(\phi_{2}=0.02\right)$ with the condition of $S=3.5$ and $R d=2$. Meanwhile, in Figure 3, the critical point is located at $S_{c 1}=2.5545\left(\phi_{2}=0.01\right), \quad S_{c 2}=2.5260\left(\phi_{2}=0.015\right) \quad$ and $S_{c 3}=2.4994\left(\phi_{2}=0.02\right) \quad$ when $\lambda=-1$ and $R d=2$. These critical points also indicate the occurrence point for boundary layer separation, by cause of the enhancement of copper volumetric concentration parameter $\phi_{2}$. 


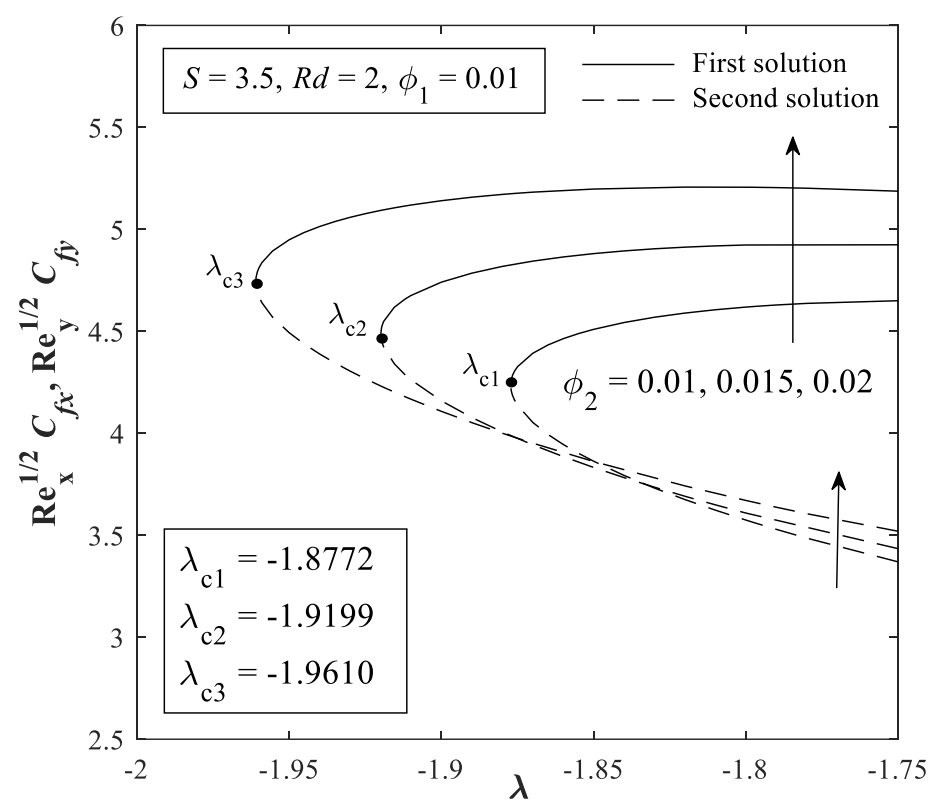

Fig. 2. The skin friction coefficients with $\lambda$ for diverse $\phi_{2}$

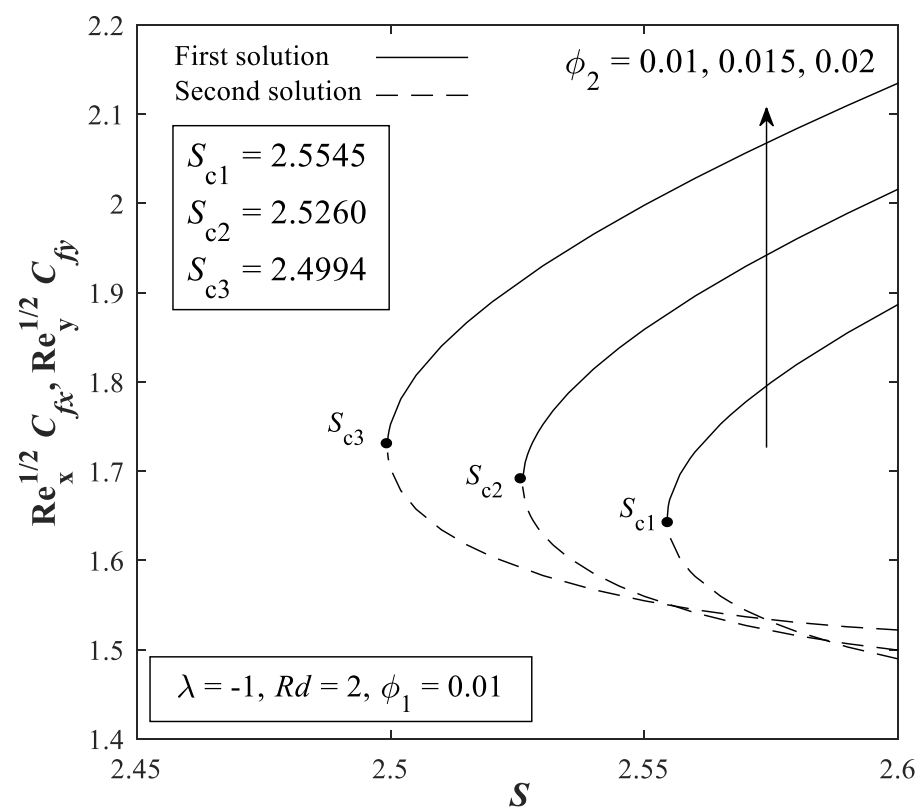

Fig. 3. The skin friction coefficients with $S$ for diverse $\phi_{2}$

The effects of copper volumetric concentration $\phi_{2}$ and thermal radiation $R d$ parameters towards the heat transfer rate which is measured by the local Nusselt number $\operatorname{Re}_{x}^{-1 / 2} N u_{x}$ are depicted in Figure 4 to Figure 7 against the shrinking surface $(\lambda<0)$ and suction $S$ parameters, accordingly. In these figures, the local Nusselt number $\operatorname{Re}_{x}^{-1 / 2} N u_{x}$ is noticed to gradually reduced when the shrinking surface $(\lambda<0)$ and suction $S$ parameters decrease. Figure 4 and Figure 5 show that the local Nusselt number $\operatorname{Re}_{x}^{-1 / 2} N u_{x}$ is affected to be reduced when the copper volumetric concentration parameter $\phi_{2}$ is enhanced in the shrinking surface region $(\lambda<0)$ for both of the solutions. The critical points are observable at the shrinking surface region $(\lambda<0)$ as well, located similarly as mentioned in Figure 2 and Figure 3 but with a different condition of thermal radiation parameter $R d$ which is set to be $R d=0.02$. This also could deduce that the thermal radiation parameter $R d$ does not affect 
the boundary layer separation point. Consequently, in Figure 6 and Figure 7, it is also noticeable that the different values of thermal radiation parameter $R d$ only approach towards the same critical point which is located at $\lambda_{c}=-1.8772$ and $S_{c}=2.5545$ for $R d=0,0.01,0.02$ against the shrinking surface $(\lambda<0)$ and suction $S$ parameters, respectively. Nevertheless, the intensification of thermal radiation parameter $R d$ leads to the enhancement of the local Nusselt number $\operatorname{Re}_{x}^{-1 / 2} N u_{x}$. In addition, it is also worth mentioning that the revelation of the critical point is important as it can signify the separation point of the boundary layer which is the point where the occurrence of the transition of the flow is changed from laminar to turbulent. Hence, to delay such occurrence, an appropriate adjustment on the parameter related to the critical point can be done to delay the separation process and to ensure the stability of the flow.

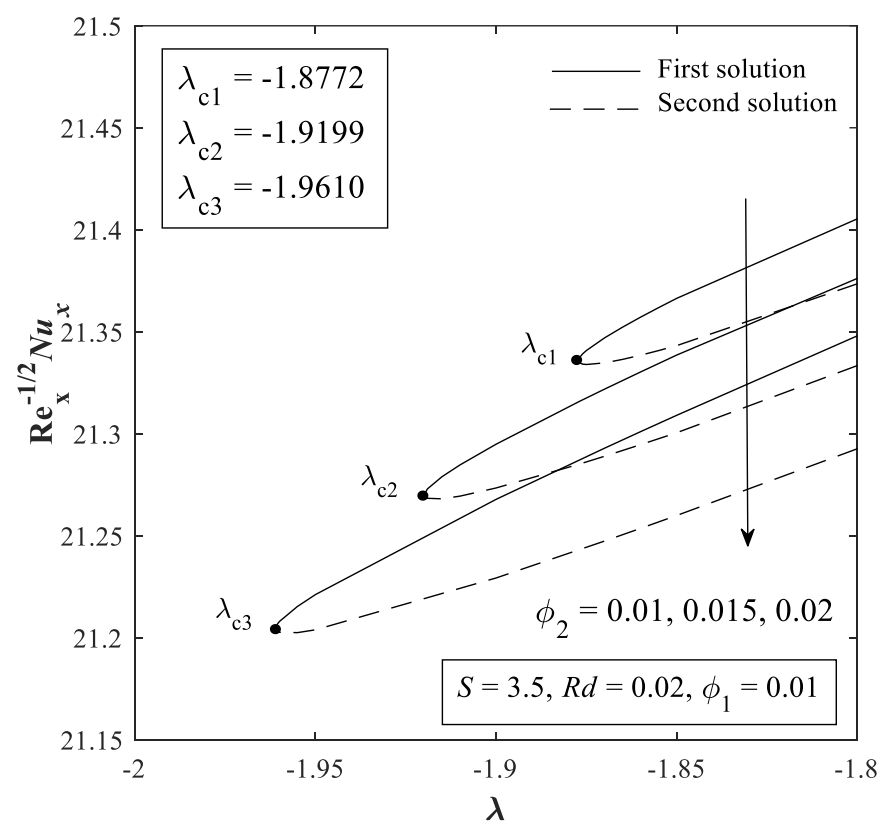

Fig. 4. The local Nusselt number with $\lambda$ for diverse $\phi_{2}$

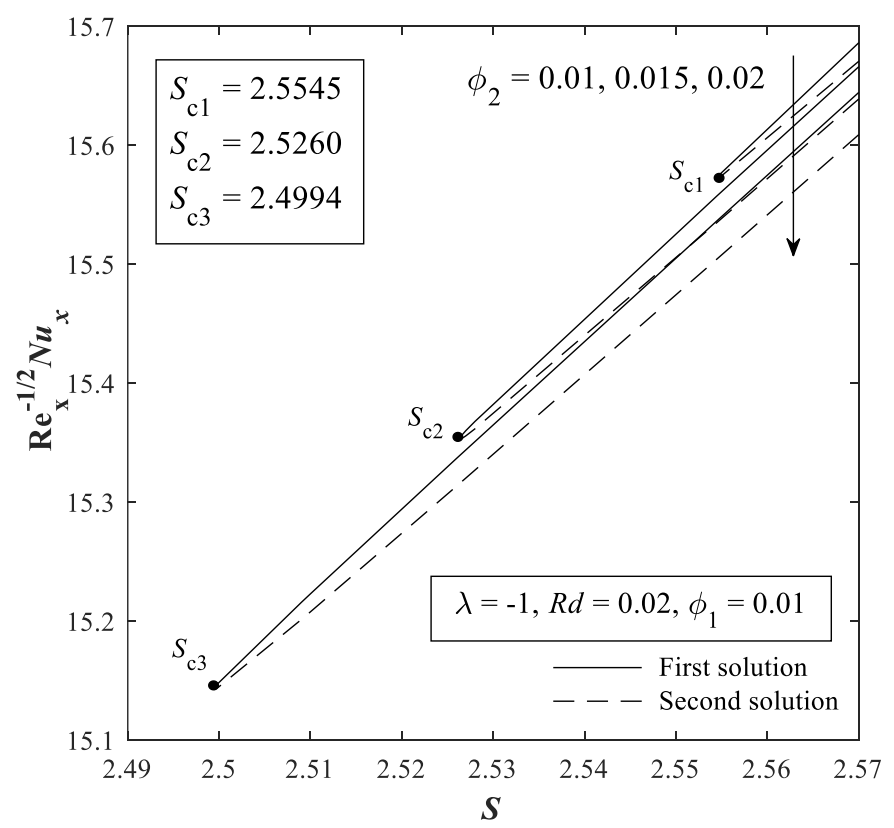

Fig. 5. The local Nusselt number with $S$ for diverse $\phi_{2}$ 


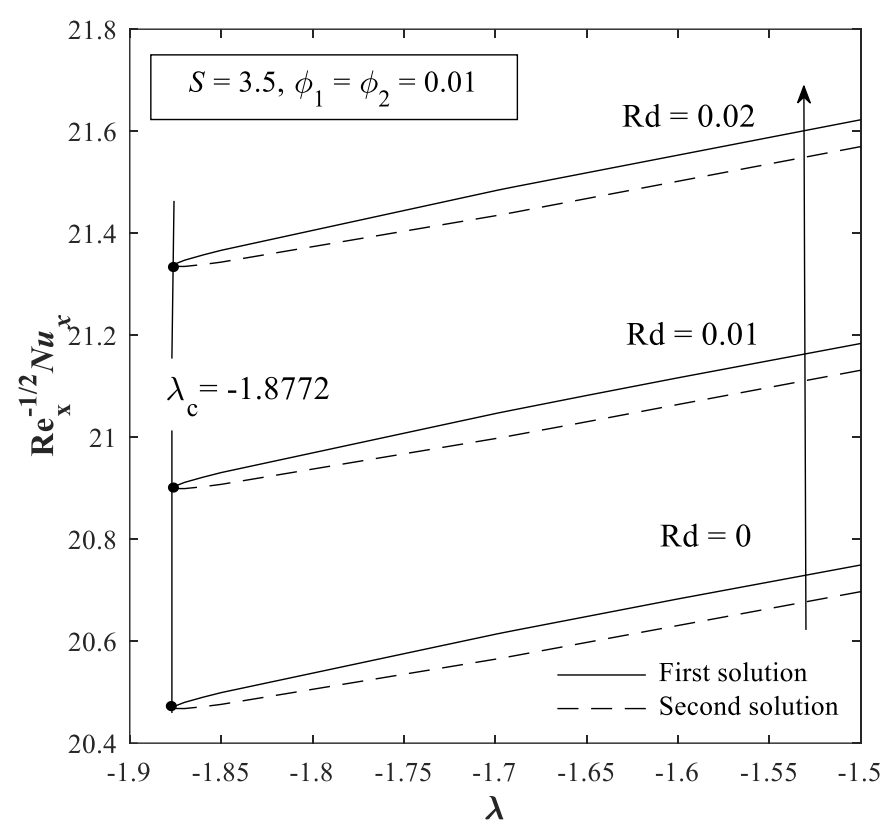

Fig. 6. The local Nusselt number with $\lambda$ for diverse $R d$

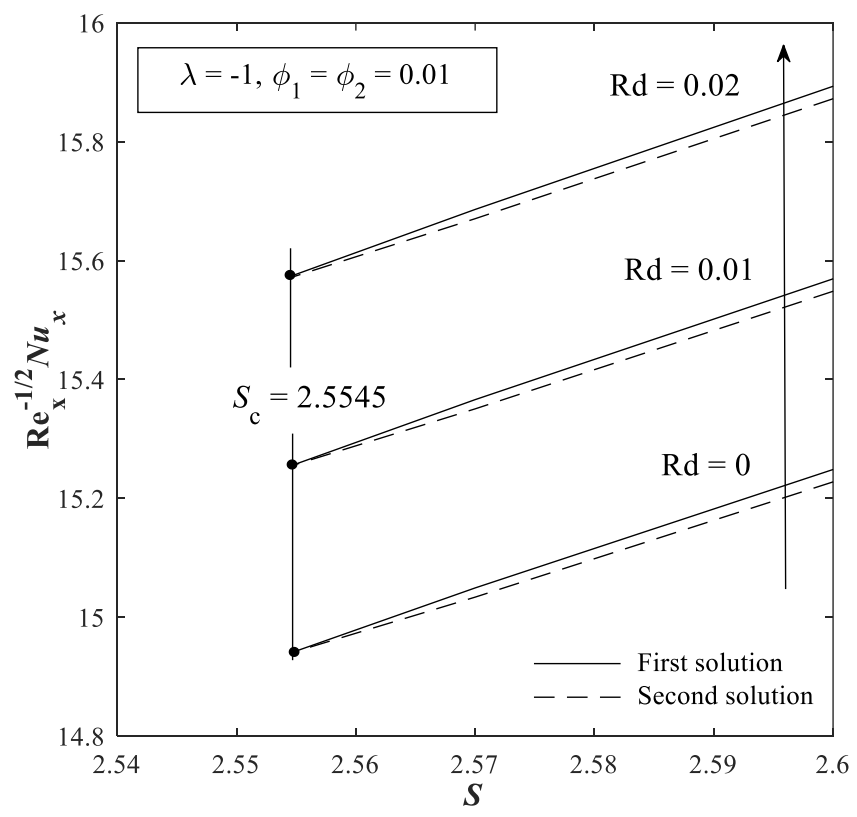

Fig. 7. The local Nusselt number with $S$ for diverse $R d$

The velocity profiles $f^{\prime}(\eta), g^{\prime}(\eta)$ and temperature profile $\theta(\eta)$ for diverse values of copper volumetric concentration $\phi_{2}$, suction $S$ and thermal radiation $R d$ parameters at the shrinking surface $(\lambda<0)$ are exhibited in Figure 8 to Figure 12 . The profiles also are seen to meet the far-field boundary layer condition. Figure 8 and Figure 9 reveals that the enhancement of copper volumetric concentration $\phi_{2}$ and suction $S$ parameters have caused the velocity profiles $f^{\prime}(\eta), g^{\prime}(\eta)$ for the first solution to accelerate and decelerate for the second solution. Meanwhile, for the temperature profile $\theta(\eta)$, as noticeable in Figure 10, the intensification of copper volumetric concentration $\phi_{2}$ has intensified the temperature profile $\theta(\eta)$ and thickening the boundary layer thicknesses for the first and second solutions. Unlikely, for the suction $S$ and thermal radiation $R d$ parameters, the 
intensification in these parameters causes the temperature profile $\theta(\eta)$ and the boundary layer thicknesses to be reduced for both solutions. In this specified case, both suction and thermal radiation parameters could act as a coolant agent.

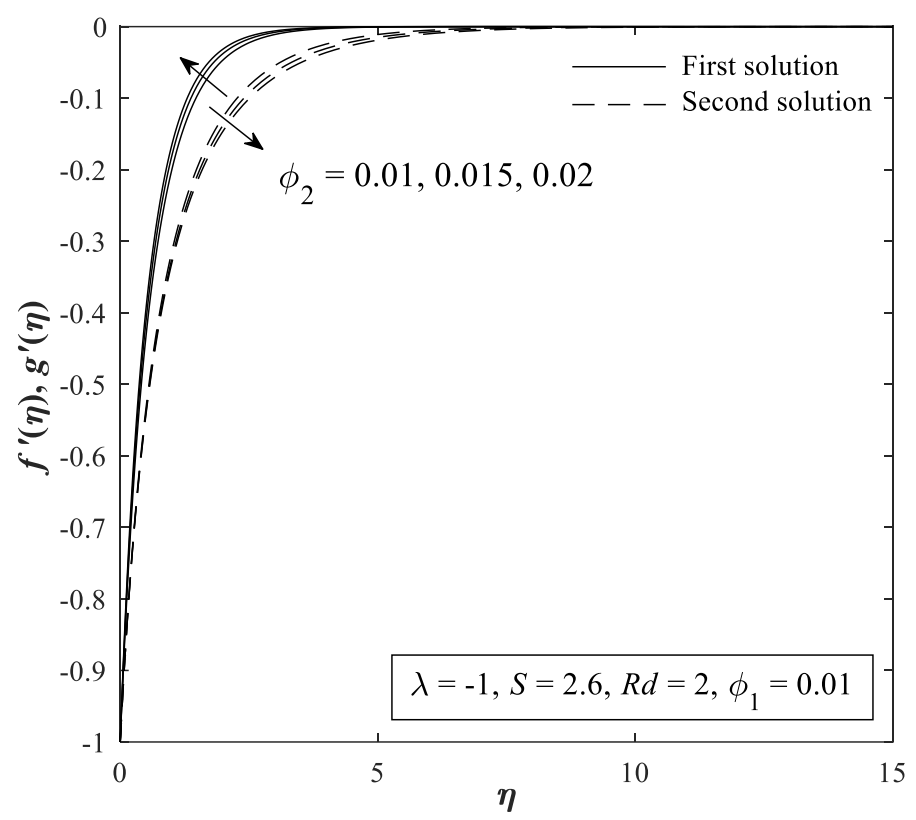

Fig. 8. Velocity profiles for diverse $\phi_{2}$

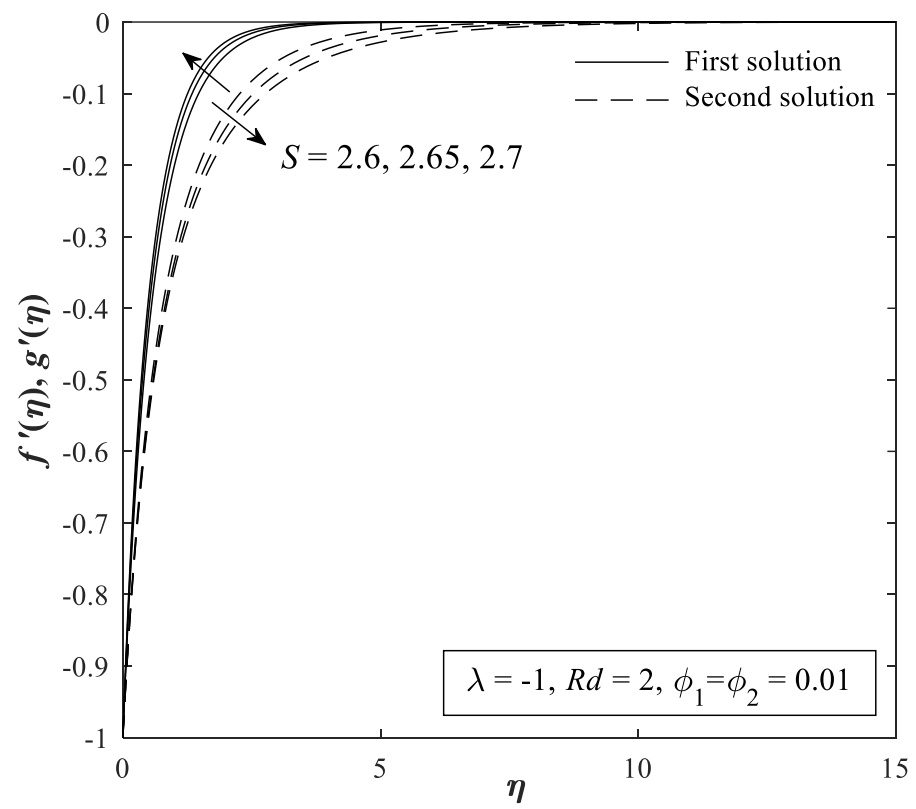

Fig. 9. Velocity profiles for diverse $S$ 


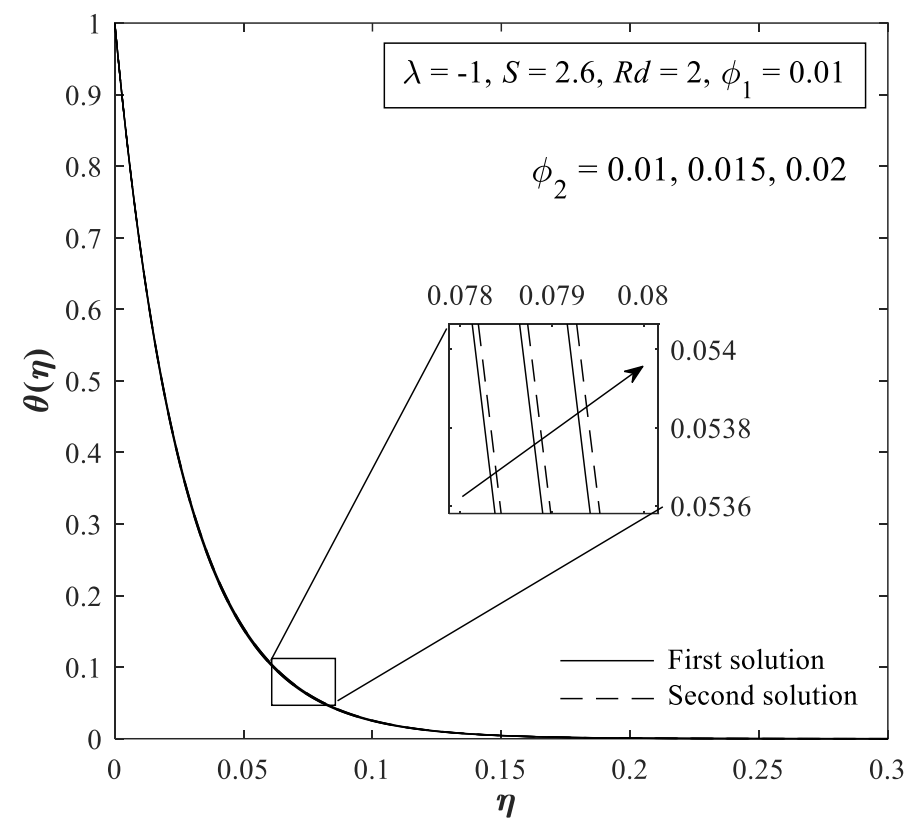

Fig. 10. Temperature profile for diverse $\phi_{2}$

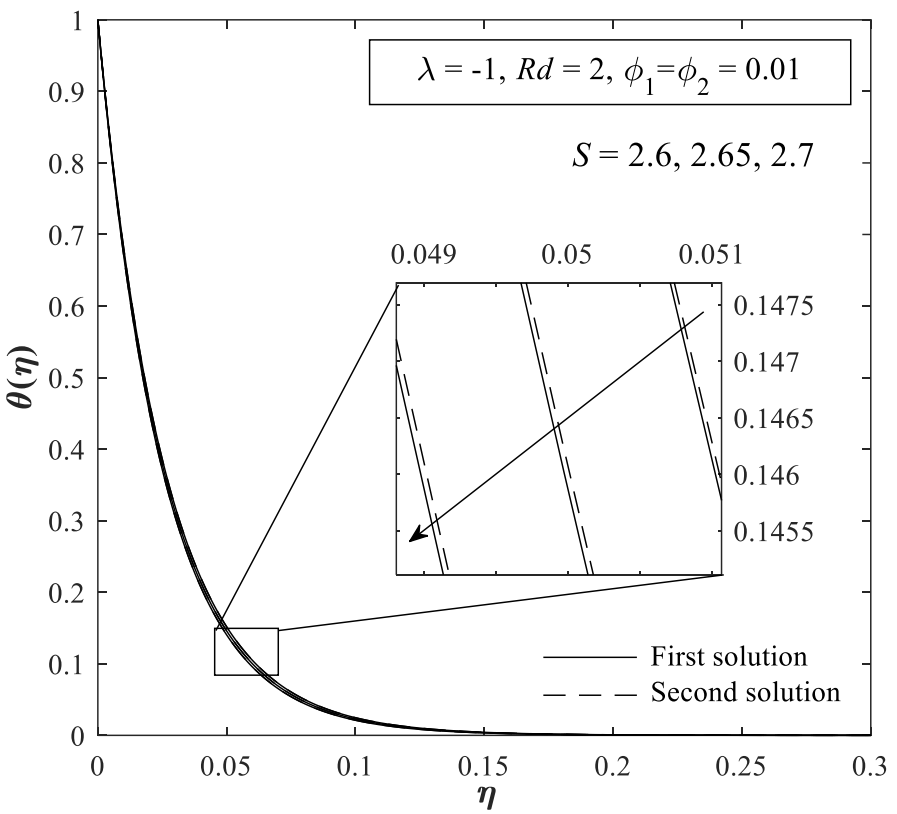

Fig. 11. Temperature profile for diverse $S$ 


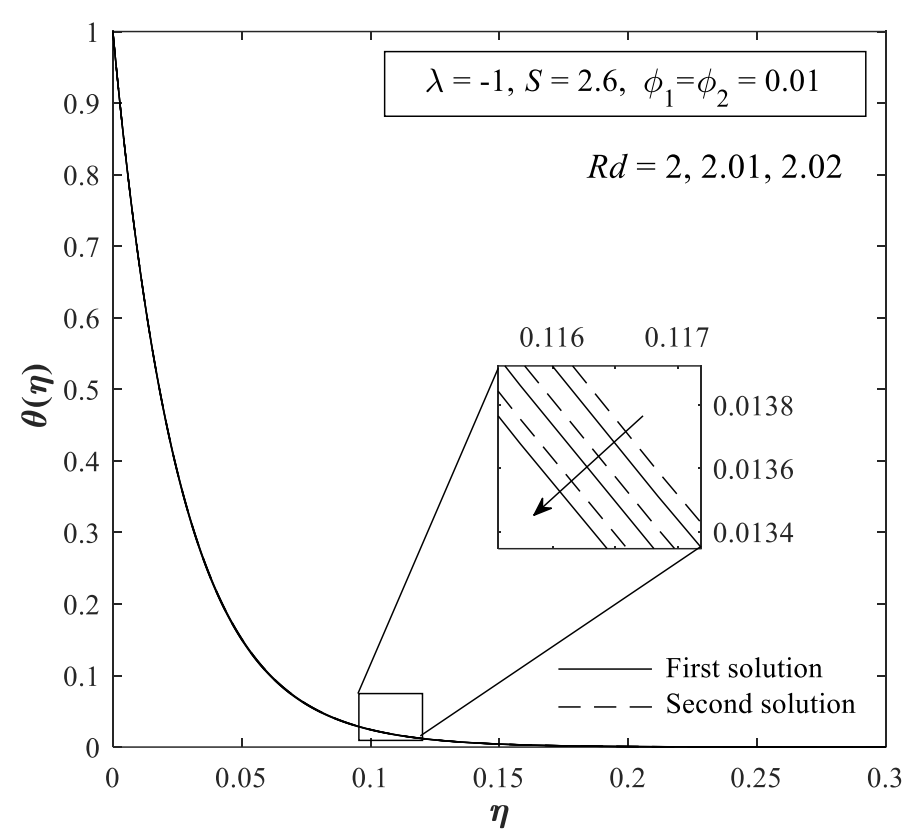

Fig. 12. Temperature profile for diverse $R d$

In this study, the stability analysis is executed in consequence to the existence of dual solutions, as to discover which solution is stable among the dual solutions. The formulation for the analysis is performed as shown in Section 3 with the aid of bvp4c solver. Figure 13 graphically presents the smallest eigenvalues $\gamma$ against the stretching/shrinking surface parameter $\lambda$ when $S=3.5, R d=2$ and $\phi_{2}=0.01$ with the selected critical point of $\lambda_{c}=-1.8772$. The first solution is noticed to have the positive smallest eigenvalues, whereas the second solution produces the negative smallest eigenvalues. This implies that the first solution is real/stable, and adversely for the other one. It is also notable that, $\gamma \rightarrow 0$ as $\lambda \rightarrow \lambda_{c}$.

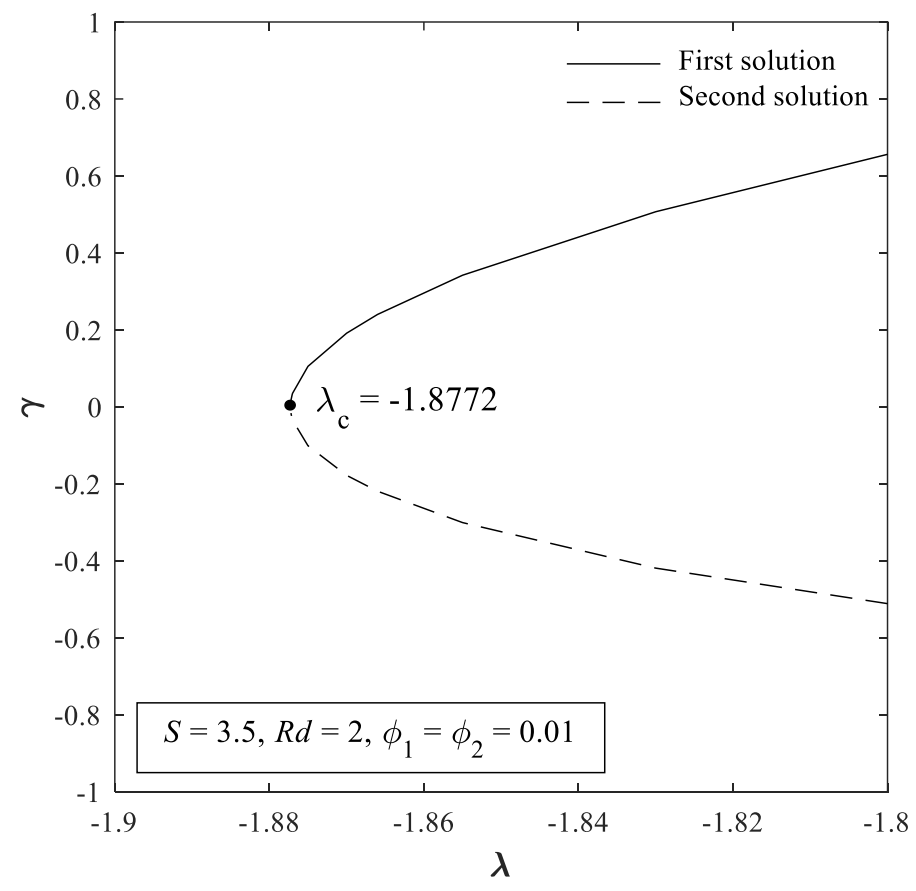

Fig. 13. The smallest eigenvalue $\gamma$ with $\lambda$ 


\section{Conclusion}

The three-dimensional flow of boundary layer for hybrid $\mathrm{Cu}-\mathrm{Al}_{2} \mathrm{O}_{3} /$ water nanofluid on a permeable shrinking plate is modeled and solved in this study. The numerical solution is computed, and the stability analysis is conducted with the used bvp4c solver (MATLAB). The results can be summarized as follows

i. Dual solutions are notable to exist, and only the first solution is real and stable.

ii. The intensification of copper volumetric concentration decelerated the boundary layer separation.

iii. The boundary layer separation is unimpacted by the thermal radiation parameter.

iv. The skin friction coefficients can be enhanced with the intensification of copper volumetric concentration.

v. The heat transfer rate is augmented with the intensification of thermal radiation parameter and is reduced with the intensification of copper volumetric concentration parameter.

vi. The reduction of stretching/shrinking surface and suction parameters leads the local Nusselt number to reduce.

vii. The velocity profiles for the first solution are enhanced with the incrementation of copper volumetric concentration and suction parameters.

viii. The temperature profile is intensified with the incrementation of copper volumetric concentration parameter but is reduced with the incrementation of suction and thermal radiation parameters.

\section{Acknowledgment}

The authors appreciatively acknowledge Universiti Putra Malaysia and Universiti Teknikal Malaysia Melaka. The financial support received from Ministry of Higher Education Malaysia through the Fundamental Research Grant Scheme (KPTFRGS/1/2019/STG06/IPM/02/3, Vot 5540309) is also gratefully acknowledged.

\section{References}

[1] Sidik, Nor Azwadi Che, Isa Muhammad Adamu, Muhammad Mahmud Jamil, G. H. R. Kefayati, Rizalman Mamat, and G. Najafi. "Recent progress on hybrid nanofluids in heat transfer applications: a comprehensive review." International Communications in Heat and Mass Transfer 78 (2016): 68-79. https://doi.org/10.1016/i.icheatmasstransfer.2016.08.019

[2] Suresh, S., K. P. Venkitaraj, P. Selvakumar, and M. Chandrasekar. "Effect of $\mathrm{Al}_{2} \mathrm{O}_{3}-\mathrm{Cu}$ /water hybrid nanofluid in heat transfer." Experimental Thermal and Fluid Science $38 \quad$ (2012): 54-60. https://doi.org/10.1016/i.expthermflusci.2011.11.007

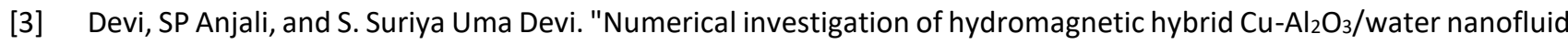
flow over a permeable stretching sheet with suction." International Journal of Nonlinear Sciences and Numerical Simulation 17, no. 5 (2016): 249-257. https://doi.org/10.1515/ijnsns-2016-0037

[4] Devi, S. Suriya Uma, and SP Anjali Devi. "Numerical investigation of three-dimensional hybrid Cu-Al2O3/water nanofluid flow over a stretching sheet with effecting Lorentz force subject to Newtonian heating." Canadian Journal of Physics 94, no. 5 (2016): 490-496. https://doi.org/10.1139/cjp-2015-0799

[5] Nadeem, S., Nadeem Abbas, and A. U. Khan. "Characteristics of three dimensional stagnation point flow of Hybrid nanofluid past a circular cylinder." Results in Physics 8 (2018): 829-835. https://doi.org/10.1016/i.rinp.2018.01.024

[6] Maskeen, Muhammad Muddassar, Ahmad Zeeshan, Obaid Ullah Mehmood, and Mohsan Hassan. "Heat transfer enhancement in hydromagnetic alumina-copper/water hybrid nanofluid flow over a stretching cylinder." Journal of Thermal Analysis and Calorimetry 138, no. 2 (2019): 1127-1136. https://doi.org/10.1007/s10973-019-08304-7

[7] Khashi'ie, Najiyah Safwa, Norihan M. Arifin, loan Pop, Roslinda Nazar, and Ezad Hafidz Hafidzuddin. "A new similarity solution with stability analysis for the three-dimensional boundary layer of hybrid nanofluids." International Journal of Numerical Methods for Heat \& Fluid Flow 31, no. 3 (2020): 809-828. https://doi.org/10.1108/HFF-04-2020-0200 
[8] Abbas, Nadeem, M. Y. Malik, M. S. Alqarni, and S. Nadeem. "Study of three dimensional stagnation point flow of hybrid nanofluid over an isotropic slip surface." Physica A: Statistical Mechanics and its Applications 554 (2020): 124020. https://doi.org/10.1016/j.physa.2019.124020

[9] Zainal, Nurul Amira, Roslinda Nazar, Kohilavani Naganthran, and loan Pop. "Unsteady three-dimensional MHD nonaxisymmetric Homann stagnation point flow of a hybrid nanofluid with stability analysis." Mathematics 8 , no. 5 (2020): 784. https://doi.org/10.3390/math8050784

[10] Khashi'ie, Najiyah Safwa, Norihan Md Arifin, Ioan Pop, Roslinda Nazar, Ezad Hafidz Hafidzuddin, and Nadihah Wahi. "Three-dimensional hybrid nanofluid flow and heat transfer past a permeable stretching/shrinking sheet with velocity slip and convective condition." Chinese Journal of Physics 66 (2020): 157-171. https://doi.org/10.1016/i.cjph.2020.03.032

[11] Zainal, S., C. Tan, C. J. Sian, and T. J. Siang. "ANSYS simulation for Ag/HEG hybrid nanofluid in turbulent circular pipe." Journal of Advanced Research in Applied Mechanics 23, no. 1 (2016): 20-35.

[12] Sidik, Nor Azwadi Che, Isa M. Adamu, and Mahmud M. Jamil. "Preparation methods and thermal performance of hybrid nanofluids." Journal of Advanced Research in Materials Science 56, no. 1 (2019): 1-10.

[13] Anuar, Nur Syazana, Norfifah Bachok, Norihan Md Arifin, and Haliza Rosali. "Effect of suction/injection on stagnation point flow of hybrid nanofluid over an exponentially shrinking sheet with stability analysis." CFD Letters 11, no. 12 (2019): 21-33. https://doi.org/10.3390/sym11040522

[14] Faizal, Nur Faizzati Ahmad, Norihan Md Ariffin, Yong Faezah Rahim, Mohd Ezad Hafidz Hafidzuddin, and Nadihah Wahi. "MHD and Slip Effect in Micropolar Hybrid Nanofluid and Heat Transfer over a Stretching Sheet with Thermal Radiation and Non-uniform Heat Source/Sink." CFD Letters 12, no. 11 (2020): 121-130. https://doi.org/10.37934/cfdl.12.11.121130

[15] Khashi'ie, Najiyah Safwa, Ezad Hafidz Hafidzuddin, Norihan Md Arifin, and Nadihah Wahi. "Stagnation point flow of hybrid nanofluid over a permeable vertical stretching/shrinking cylinder with thermal stratification effect." CFD Letters 12, no. 2 (2020): 80-94.

[16] Wahid, Nur Syahirah, Norihan Md Arifin, Mustafa Turkyilmazoglu, Mohd Ezad Hafidz Hafidzuddin, and Nor Aliza Abd Rahmin. "MHD hybrid $\mathrm{Cu}-\mathrm{Al}_{2} \mathrm{O}_{3} /$ water nanofluid flow with thermal radiation and partial slip past a permeable stretching surface: analytical solution." In Journal of Nano Research, vol. 64, pp. 75-91. Trans Tech Publications Ltd, 2020. https://doi.org/10.4028/www.scientific.net/JNanoR.64.75

[17] Najiyah Safwa Khashi'ie, Norihan Md Arifin and Ioan Pop, “ Mixed Convective Stagnation Point Flow towards a vertical Riga Plate in Hybrid $\mathrm{Cu}-\mathrm{Al}_{2} \mathrm{O}_{3}$ /Water nanofluid," Mathematics 8, no. 6 (2020): 912. https://doi.org/10.3390/math8060912

[18] Wahid, Nur Syahirah, Norihan Md Arifin, Najiyah Safwa Khashi'ie, and loan Pop. "Hybrid nanofluid slip flow over an exponentially stretching/shrinking permeable sheet with heat generation." Mathematics 9, no. 1 (2021): 30. https://doi.org/10.3390/math9010030

[19] Wahid, Nur Syahirah, Norihan Md Arifin, Najiyah Safwa Khashi'ie, loan Pop, Norfifah Bachok, and Mohd Ezad Hafidz Hafidzuddin. "Flow and heat transfer of hybrid nanofluid induced by an exponentially stretching/shrinking curved surface." Case Studies in Thermal Engineering 25 (2021): 100982. https://doi.org/10.1016/i.csite.2021.100982

[20] Khan, Umair, Iskandar Waini, Anuar Ishak, and loan Pop. "Unsteady hybrid nanofluid flow over a radially permeable shrinking/stretching surface." Journal of Molecular Liquids $331 \quad$ (2021): 115752. https://doi.org/10.1016/i.molliq.2021.115752

[21] Rashid, Umair, Haiyi Liang, Hijaz Ahmad, Muhammad Abbas, Azhar Iqbal, and Y. S. Hamed. "Study of (Ag and $\mathrm{TiO}_{2}$ )/water nanoparticles shape effect on heat transfer and hybrid nanofluid flow toward stretching shrinking horizontal cylinder." Results in Physics 21 (2021): 103812. https://doi.org/10.1016/i.rinp.2020.103812

[22] Ullah, Habib, T. Hayat, Salman Ahmad, M. Sh Alhodaly, and Shaher Momani. "Numerical simulation of MHD hybrid nanofluid flow by a stretchable surface." Chinese Journal of Physics 71 (2021): 597-609. https://doi.org/10.1016/i.cjph.2021.03.017

[23] Abu Bakar, Shahirah, Norihan Md Arifin, Najiyah Safwa Khashi'ie, and Norfifah Bachok. "Hybrid Nanofluid Flow over a Permeable Shrinking Sheet Embedded in a Porous Medium with Radiation and Slip Impacts." Mathematics 9 , no. 8 (2021): 878. https://doi.org/10.3390/math9080878

[24] Rosseland, Svein. "Astrophysik auf atomtheoretischer Grundlage." Struktur der Materie in Einzeldarstellungen (1931). https://doi.org/10.1007/978-3-662-26679-3

[25] Takabi, Behrouz, and Saeed Salehi. "Augmentation of the heat transfer performance of a sinusoidal corrugated enclosure by employing hybrid nanofluid." Advances in Mechanical Engineering 6 (2014): 147059. https://doi.org/10.1155/2014/147059

[26] Oztop, Hakan F., and Eiyad Abu-Nada. "Numerical study of natural convection in partially heated rectangular enclosures filled with nanofluids." International Journal of Heat and Fluid Flow 29, no. 5 (2008): 1326-1336. https://doi.org/10.1016/i.ijheatfluidflow.2008.04.009 
[27] Merkin, J. H. "On dual solutions occurring in mixed convection in a porous medium." Journal of Engineering Mathematics 20, no. 2 (1986): 171-179. https://doi.org/10.1007/BF00042775

[28] Harris, S. D., D. B. Ingham, and I. Pop. "Mixed convection boundary-layer flow near the stagnation point on a vertical surface in a porous medium: Brinkman model with slip." Transport in Porous Media 77, no. 2 (2009): 267-285. https://doi.org/10.1007/s11242-008-9309-6

[29] Jusoh, Rahimah, Roslinda Nazar, and Ioan Pop. "Flow and heat transfer of magnetohydrodynamic threedimensional Maxwell nanofluid over a permeable stretching/shrinking surface with convective boundary conditions." International Journal of Mechanical Sciences 124 (2017): 166-173. https://doi.org/10.1016/i.ijmecsci.2017.02.022

[30] Hayat, Tasawar, Sabir Ali Shehzad, Muhammad Qasim, and Saleem Asghar. "Three-dimensional stretched flow via convective boundary condition and heat generation/absorption." International Journal of Numerical Methods for Heat \& Fluid Flow 24, no. 2 (2014): 342-358. https://doi.org/10.1108/HFF-03-2012-0065 